\title{
Monitoring of Structural Performance of Early-age Concrete Pavement
}

\author{
Jaewook Ku, ${ }^{1}$ Seunghyun Roh, ${ }^{2}$ and Hyunsik Hwang ${ }^{2 *}$ \\ ${ }^{1}$ SMART Highway R\&D Division, Korea Expressway Corporation, \\ 77, Hyeoksin 8-ro, Gimcheon-si, Gyeongsangbuk-do 39660, Republic of Korea \\ ${ }^{2}$ Department of Civil and Environmental Engineering, Chung-Ang University, \\ 84 HeukSeok-Dong, Dong-Jak-Gu, Seoul 06974, Republic of Korea
}

(Received December 1, 2021; accepted January 4, 2022)

Keywords: Portland cement concrete pavement, concrete shrinkage, concrete monitoring, measurement

Early-age concrete shrinkage induces stress, which affects the cost and service life of concrete pavements. Concrete construction quality assurance has been evaluated as an experiment test, but in this paper, a performance monitoring method for initial concrete quality management using sensors was proposed. To monitor the behavior of Portland cement concrete, strain measurements of field slabs were conducted, and a methodology was presented that independently derived autogenous, drying, and thermal shrinkage in the initial stages of concrete placement using strain sensors. Total strain was measured under five different environmental conditions and shrinkage strain was calculated for each condition. By measuring the strain of the slab and the specimen, the drying shrinkage strain range was measured to be approximately $54 \%$ higher than that measured by the conventional non-stressed cylinder method because it was possible to measure the drying shrinkage strain at the surface rather than in the middle part of the slab along its depth direction. Furthermore, calculation of the stress-dependent strain allowed the presentation of more intuitive and accurate results. As the monitoring of independent shrinkage occurrence is possible, the consequent calculated result of the stressdependent strain acting on real slabs will help improve the construction quality, reduce the development of defects in concrete structures, and increase the service life.

\section{Introduction}

Concrete is the most extensively used construction material worldwide. Portland cement concrete pavement was first designed in the United States in 1892. Since then, concrete has been applied as a paving material for various infrastructures such as roads, ports, and airports. ${ }^{(1)}$ As the safety and durability of these infrastructures are critical, the cost of repair and the service life need to be assessed carefully. The service life of concrete is evaluated in terms of physical strength, durability, and serviceability.

The physical strength of concrete varies with age and setting time. During this early-age period, two main reactions occur: a setting process with a progressive loss of fluidity and a

${ }^{*}$ Corresponding author: e-mail: cau.hhs@gmail.com

https://doi.org/10.18494/SAM3761 
hardening process with an increase in strength. ${ }^{(2)}$ During the process of hydration, concrete undergoes a transition from a fluid to a hardened structure; however, before the final setting, concrete does not develop sufficient tensile strength. Hence, the use of concrete before the final setting leads to a high risk of defect formation. Accordingly, proper quality control is necessary in construction. ${ }^{(3)}$

Shrinkage occurs in concrete during the hydration process. For general concrete, in the first phase (within $24 \mathrm{~h}$ after placement), the unhardened concrete begins to harden, and chemical shrinkage occurs during the setting process. The second phase refers to the period $\sim 24 \mathrm{~h}$ after placement, wherein autogenous, drying, and thermal shrinkage occur. The three types of shrinkage yield the same outcome in terms of concrete materials, but each type of shrinkage is caused by a different mechanism. ${ }^{(4-8)}$ The process from the placement of concrete to its final setting is illustrated in Fig. 1.

Drying shrinkage is a consequence of loss of moisture from hardened concrete to the environment. Following moisture diffusion from the surface to the outside, shrinkage is caused by changes in the capillary pressure, disjoining pressure, and surface tension. ${ }^{(9,10)}$ Previous studies have reported that when the distribution of moisture in the cross section of concrete is not uniform, greater shrinkage is induced on the surface, thus resulting in tensile stress. The shrinkage will progress over a long time until the cement's humidity equilibrates with that of the external environment, thus seriously affecting the durability of the concrete. ${ }^{(11)}$ Drying shrinkage decreases with increasing strength and decreasing water-to-cement ratio (w/c ratio), but is significantly affected by external factors, such as the size of the member and relative humidity. ${ }^{(12,13)}$ However, the final drying shrinkage increases as the relative humidity decreases, and the size of the member may affect the rate of progress of drying shrinkage but not the final amount of drying shrinkage. Drying shrinkage cracks formed on the surface typically propagate

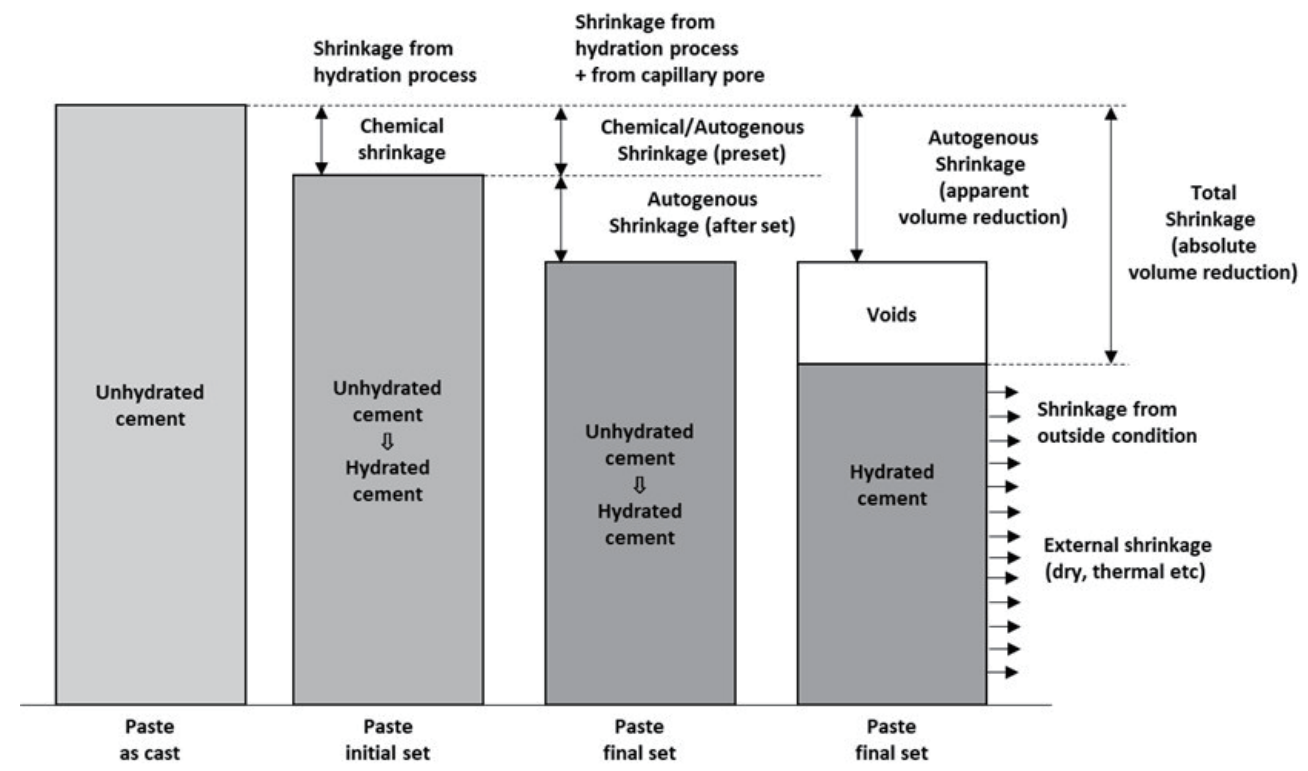

Fig. 1. Concrete shrinkage process from its placement to the final setting. 
to a depth of 2-3 cm from the surface, which may not cause a significant problem in the initial phase; however, these cracks may develop and become a major cause of durability defects during long-term use. ${ }^{(14)}$

Among the various types of concrete shrinkage at the initial stage of placement, autogenous shrinkage can be defined as the macroscopic volume change that occurs after the initial setting as a result of the elimination of moisture from capillary pores in continuing cement hydration reactions. ${ }^{(15)}$ The process of autogenous shrinkage can be described as a process of selfdesiccation in which unhydrated cement particles during the early stage of hardening gradually eliminate the internal moisture and undergo hydration and contraction. ${ }^{(16)}$ Nowadays, concrete exhibits high strength/durability, achieved by lowering the w/c ratio and adding silica fume. However, reports have indicated that the change in the internal humidity from hydration heat increases, and this has a dominant impact on the occurrence of early cracks. ${ }^{(17)}$ These findings indicate that in the case of high-strength (high-performance) concrete, cracks can be formed owing to changes in the volume. ${ }^{18)}$ Another study reported that in the case of autogenous shrinkage, pore humidity drops owing to internal hydration, and it is not affected by the depth of the mixture or ambient humidity. ${ }^{(19)}$

Conventional methods for measuring the autogenous shrinkage strain or volume change involved placing cement paste in a rubber membrane, immersing it in a water bath, and measuring the shrinkage by the change in the water level. ${ }^{(20)}$ In another method (Fig. 2), stressdependent strain was derived using a non-stressed cylinder (NC) for the in situ evaluation of initial stress generation for concrete structures. ${ }^{(21-23)}$

Among these methods, the NC concept was used as a reference method for comparison in this study. Total strain can be divided into four types of strain (i.e., elastic, creep, shrinkage, and thermal):

$$
\varepsilon(t)=\varepsilon^{E}(t)+\varepsilon^{C}(t)+\varepsilon^{S}(t)+\varepsilon^{T}(t)=\varepsilon^{\sigma}(t)+\varepsilon^{0}(t),
$$

where $\varepsilon(t)$ is the total strain, $\varepsilon^{E}(t)$ is the elastic strain, $\varepsilon^{C}(t)$ is the creep strain, $\varepsilon^{S}(t)$ is the shrinkage strain, $\varepsilon^{T}(t)$ is the thermal strain, $\varepsilon^{\sigma}(t)=\varepsilon^{E}(t)+{ }_{\varepsilon}^{C}(t)$ is the stress-dependent strain, and $\varepsilon^{0}(t)=\varepsilon^{S}(t)+\varepsilon^{T}(t)$ is the stress-independent strain.
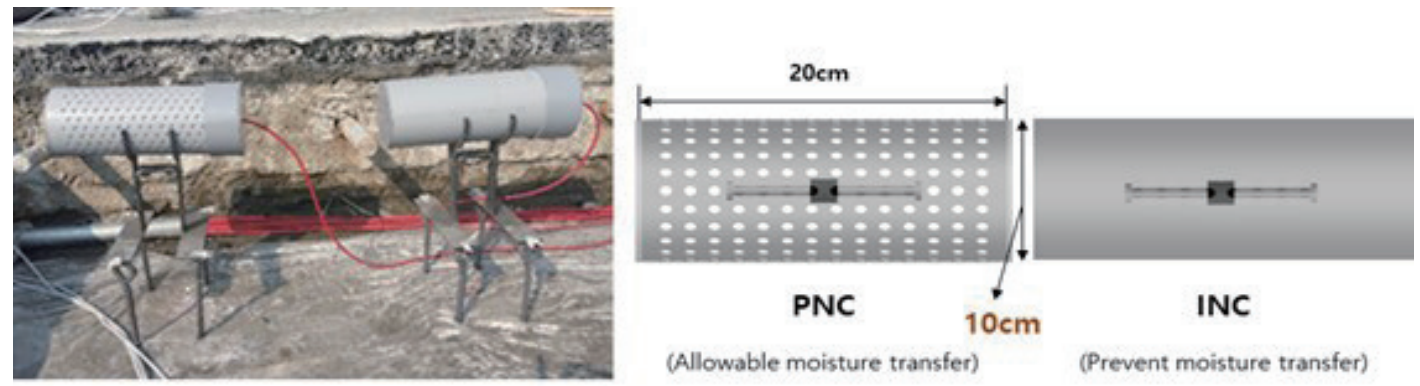

Fig. 2. (Color online) Evaluation method of early-age concrete using NC in field. 
This study presents a methodology to derive independent drying and autogenous shrinkage in the initial stage of concrete placement. By this newly developed monitoring method of independent shrinkage occurrence, improved construction quality, fewer developed defects in concrete structures, and increased service life are expected on the basis of the calculation result of the stress-dependent strain acting on actual slabs. This paper also provides an evaluation method through quantitative measurement using sensors to improve the limitations of the empirical quality management method of concrete pavement.

\section{Materials and Methods}

The basic concept used for the measurement of the shrinkage behavior of early-age concrete is presented schematically in Fig. 3. First, consider the difference between a cantilever beam, in which strain (but no stress) develops due to temperature changes, and a fixed-end beam in which both ends are fixed (thus, it has stress but no strain). In the case of a beam specimen, rollers are installed at both ends of the bottom part of the specimen to induce cantilever-like behavior in a free beam. In addition, for the field slab, a fixed end-beam behavior is induced owing to friction at the bottom part of the specimen to evaluate the shrinkage behavior of early-age concrete.

The conventional NC method and the proposed method of fabricating an environmentcontrolled beam were evaluated and compared using the aforementioned concept. For the proposed methodology, as shown in Fig. 4, the entire front surface of two beam specimens was
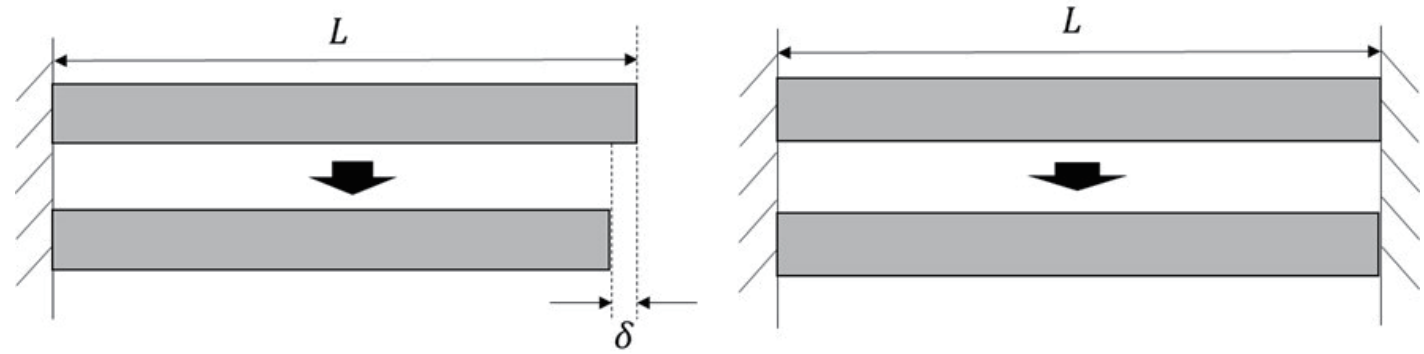

Fig. 3. Basic concept adopted for the measurement of shrinkage behavior.

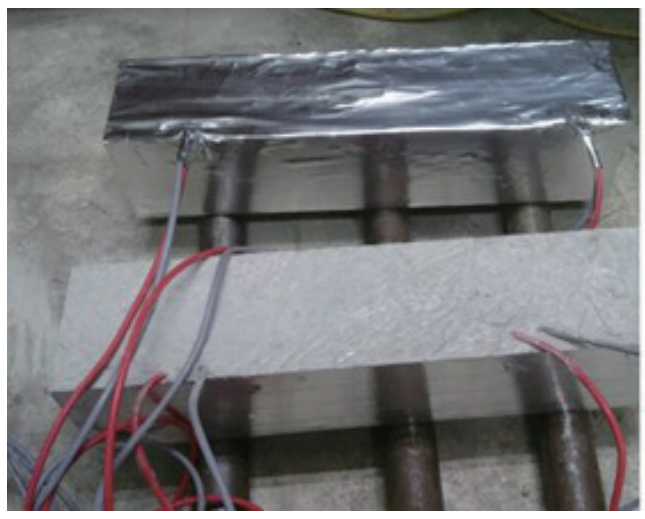

(a)

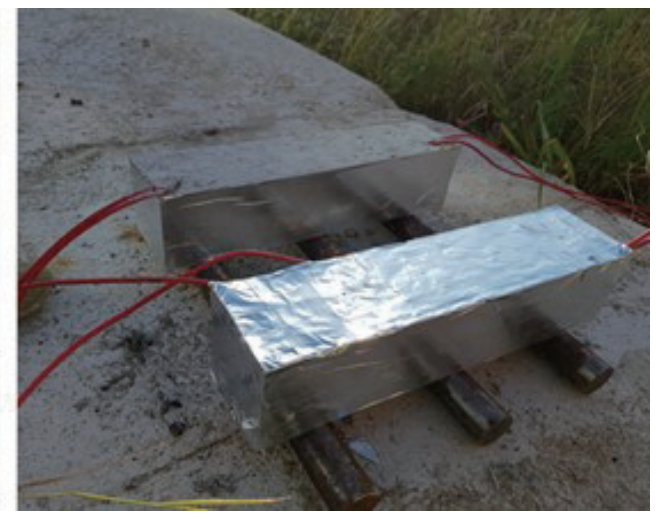

(b)

Fig. 4. (Color online) Environment-controlled specimens in (a) chamber and (b) field. 
wrapped with aluminum tape; the surface of two more specimens was exposed to air to fabricate a total of four specimens. A GEOKON Vibrating Wire Strain Gage (VWSG) sensor was installed at a depth of $3 \mathrm{~cm}$ from the surface layer of the specimen and field slab to evaluate the effect of surface drying.

In particular, in an environment where the temperature is kept constant (e.g., in a chamber in which the specimen has its front surface covered with aluminum tape), there is no influence from the external environment, and shrinkage is only due to early-age hydration. In the experimental setup, as shown in Fig. 5, the all-blocked specimen undergoes shrinkage regardless of the location, whereas the top-open specimen is exposed to the external environment and different levels of shrinkage are measured depending on the depth of the specimen. On the basis of these differences, each shrinkage may occur during the hydration process of early-age cement concrete.

The top-open and all-blocked specimens were in the field and an environmental chamber, respectively, and the temperature and humidity conditions were varied as shown in Table 1. $\varepsilon_{1}$ represents a top-open specimen in the field and is subject to all the effects of thermal, drying, and autogenous shrinkage. $\varepsilon_{2}$ represents an all-blocked specimen in the field, which reflects the effect of temperature but blocks humidity to maintain the change in humidity due to external influences. $\varepsilon_{3}$ represents a top-open specimen in an environmental chamber with temperature and humidity controlled at constant values of $20{ }^{\circ} \mathrm{C}$ and $50 \%$, respectively. Humidity loss through the surface was possible. Thus, only drying and autogenous shrinkage occurred in the specimen. $\varepsilon_{4}$ represents an all-blocked specimen in an environmental chamber in which the
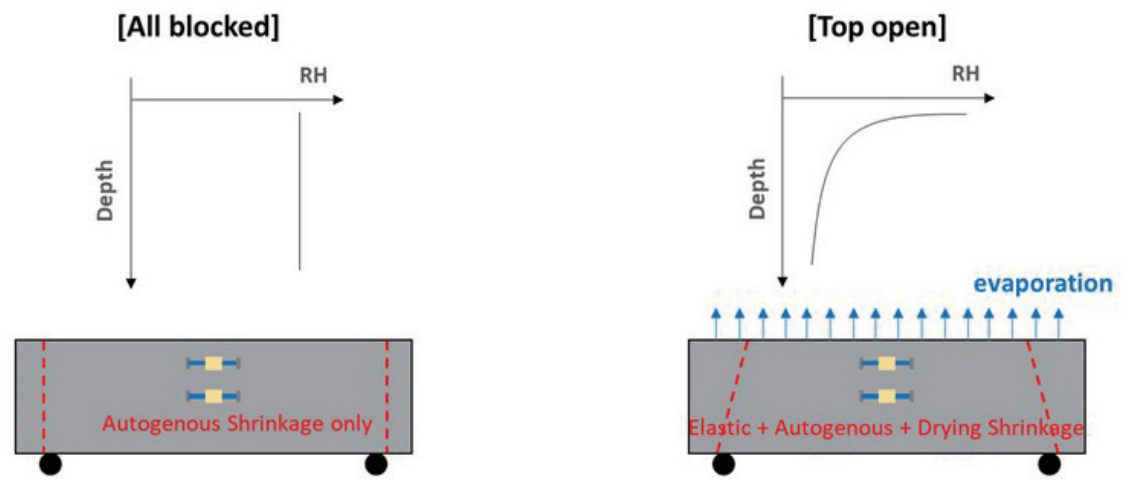

Fig. 5. (Color online) Concept of environment control method for measuring each shrinkage strain.

Table 1

Definition of shrinkage conditions to evaluate concrete's early-age behavior.

\begin{tabular}{|c|c|c|c|c|c|}
\hline \multirow{3}{*}{ Condition } & \multicolumn{4}{|c|}{ Beam specimen } & \multirow{3}{*}{ Field slab } \\
\hline & \multicolumn{2}{|c|}{ Field } & \multicolumn{2}{|c|}{ Chamber } & \\
\hline & Top open & All blocked & Top open & All blocked & \\
\hline Temperature & Change & Change & Steady & Steady & Change \\
\hline Humidity & Change & Steady & Change & Steady & Change \\
\hline Simulation & $\begin{array}{l}\text { (Thermal + Drying } \\
+ \text { Autogenous) }\end{array}$ & $\begin{array}{l}\text { (Thermal + } \\
\text { Autogenous) }\end{array}$ & $\begin{array}{c}\text { (Drying }+ \\
\text { Autogenous) }\end{array}$ & (Autogenous) & $\begin{array}{c}\text { (Thermal + Drying } \\
+ \text { Autogenous) }\end{array}$ \\
\hline Symbol & $\mathrm{a}\left(\varepsilon_{1}\right)$ & $\mathrm{b}\left(\varepsilon_{2}\right)$ & $\mathrm{c}\left(\varepsilon_{3}\right)$ & $\mathrm{d}\left(\varepsilon_{4}\right)$ & $\mathrm{e}\left(\varepsilon_{5}\right)$ \\
\hline
\end{tabular}


temperature and humidity are controlled, and only autogenous shrinkage can occur. Finally, $\varepsilon_{5}$ represents the same conditions as $\varepsilon_{1}$; however, the sensor is installed in the field slab and not the beam specimen to measure the total strain in real-life pavement.

From the concept of the $\mathrm{NC}$ for thermal strain measurement, the impervious $\mathrm{NC}$ (INC) specimen embedded in the field was free from external stress, and only the strain caused by the effect of temperature occurred in the specimen. Conversely, in the proposed methodology, given that autogenous shrinkage strain occurred under all conditions, from the strain of the all-blocked specimen installed in the field, the strain of the all-blocked specimen in the chamber with only the autogenous shrinkage strain measured was subtracted to derive the pure thermal strain.

As the drying shrinkage strain measured according to the $\mathrm{NC}$ concept, the value obtained by subtracting the INC strain from the strain of the porous NC (PNC) specimen was reported. However, NC specimens can be installed in the middle part of the pavement (along its depth direction). Nevertheless, this introduces a limitation in that the reported shrinkage will not reflect the most critical drying shrinkage on the pavement surface. In the proposed new methodology, only the drying shrinkage strain, which develops on the pavement surface, can be derived by subtracting the strain of the all-blocked specimen $\left(\varepsilon_{2}\right)$ from that of the top-open specimen $\varepsilon_{1}$ in the field.

Stress-dependent strain is calculated as the difference between the strain $\varepsilon_{1}$ of the free-beam specimen and the total strain $\varepsilon_{5}$ generated by the real environmental load of the field slab whose lower motion is restricted.

The material used to investigate the behavior of the early-age concrete is a mixture of joint concrete pavement (JCP) and type 1 cement. Two mix designs were selected according to the results of a previous study that reported a significant increase in autogenous shrinkage strain when the w/c ratio was less than $40 \%,{ }^{(24)}$ as shown in Table 2.

\section{Results}

\subsection{Test method validation}

Concrete shrinks as the heat of hydration decreases after volume expansion from the earlyage hydration stage; hence, it is important to define the point at which the stress becomes zero. For the calculation of shrinkage strain, a reference point of zero strain is required, and the temperature of the concrete at this point is referred to as the zero-strain temperature (ZST). According to results from previous studies, the reduction factor, which quantifies the relationship between ZST and the peak hydration temperature, ranges from 6 to $8 \%$ on average depending on

Table 2

Cement concrete mix design (W/C: water-to-cement ratio, S/A: sand-to-aggregate ratio).

\begin{tabular}{ccccccccc}
\hline $\begin{array}{c}\text { Maximum } \\
\text { aggregate } \\
\text { size }(\mathrm{mm})\end{array}$ & $\begin{array}{c}\text { Slump } \\
(\mathrm{cm})\end{array}$ & $\begin{array}{c}\text { W/C } \\
(\%)\end{array}$ & $\begin{array}{c}\text { S/A } \\
(\%)\end{array}$ & Water & Cement & Sand & Aggregate $\begin{array}{c}\text { Mineral } \\
\text { admixture }\end{array}$ \\
\hline 25 & 2.5 & 35 & 38 & 150 & 440 & 600 & 1200 & $2-5$ \\
\hline 25 & $8 \pm 2.5$ & 40 & 46.6 & 121 & 390 & 856 & 902 & 2.34 \\
\hline
\end{tabular}




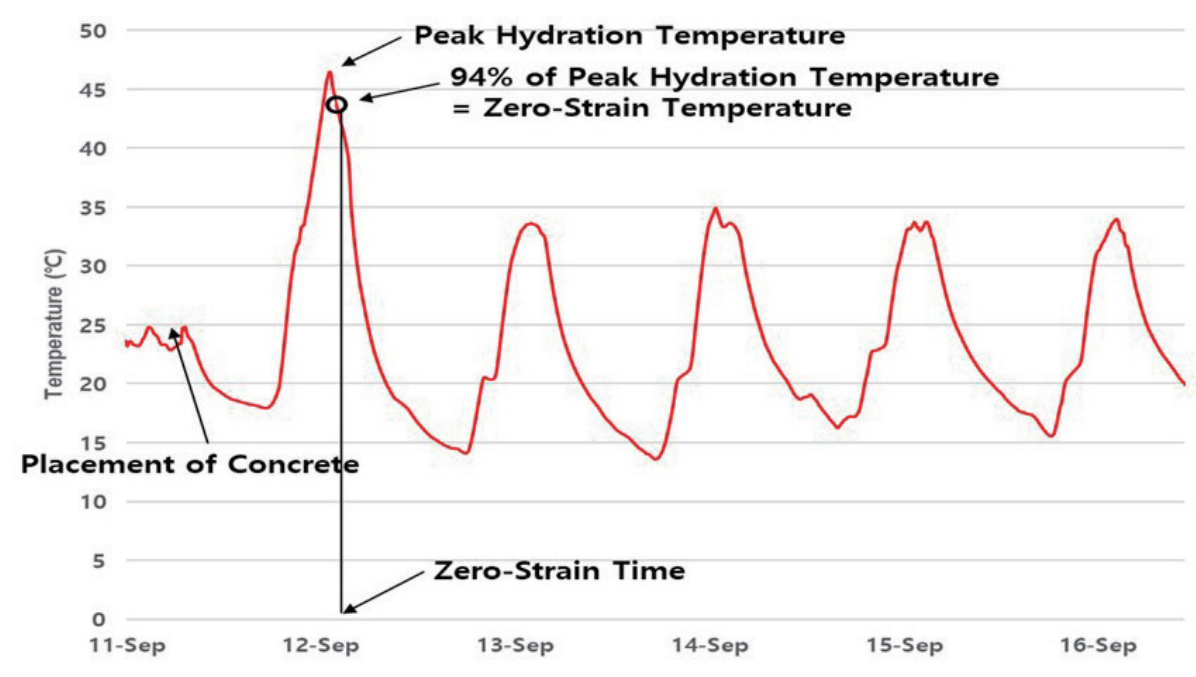

Fig. 6. (Color online) Method adopted to select the ZST.

various parameters, thus indicating that ZST occurs at 92 to $94 \%$ of the peak hydration temperature of concrete. ${ }^{(25)}$ In this study, $94 \%$ of the peak hydration temperature was defined as ZST as shown in Fig. 6.

A preliminary test was first conducted to validate the specimen evaluation method under different environmental conditions using the aluminum tape. Two VWSG sensors were embedded for each of the four beam specimens at 3 and $5 \mathrm{~cm}$ from the surface layer. Two specimens were installed in an environment-controlled chamber with temperature and humidity controlled at constant values (temperature: $20^{\circ} \mathrm{C}$, humidity: 50\%), and the other two specimens were exposed to the environment and were thus subjected to changes in temperature and humidity. In the preliminary test, evaluation was performed with the w/c ratio set at $35 \%$.

The results of the preliminary test (shown in Fig. 7) indicate that there was a difference in strain in the top-open specimens for both the field and chamber specimens. The strain at $3 \mathrm{~cm}$ from the surface layer was approximately $100-150 \mu \varepsilon$ larger than that at $5 \mathrm{~cm}$. Conversely, when the entire front surface of the specimen was blocked with aluminum tape, the difference between 3 and $5 \mathrm{~cm}$ strains was $20 \mu \varepsilon$ or less, which yielded similar results for the two cases.

The result signifies that with the methodology proposed in this study, the environmental conditions for the early-age behavior analysis of a concrete mixture can be controlled, and drying and autogenous shrinkage of the mixture can be measured.

\subsection{Measurement of environment-controlled total strain}

As shown in Fig. 8, the field slab was a square of $6 \mathrm{~m}$ length and $0.42 \mathrm{~m}$ height; this is classified as a thick cement concrete pavement. As outlined in Table 3, strain sensors were installed at the top, middle, and bottom parts to measure the total strain of the field slab. The conventional $\mathrm{NC}$ used in previous studies was also installed. Two environment-controlled beam specimens were installed, one in the field and one in the chamber, and two different conditions of top-open and all-blocked were applied. 


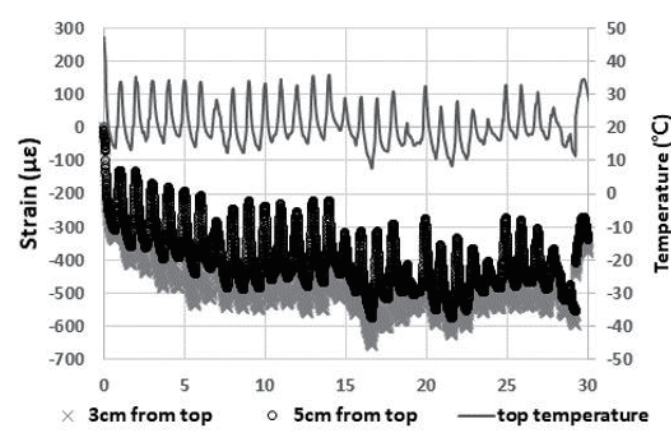

(a)

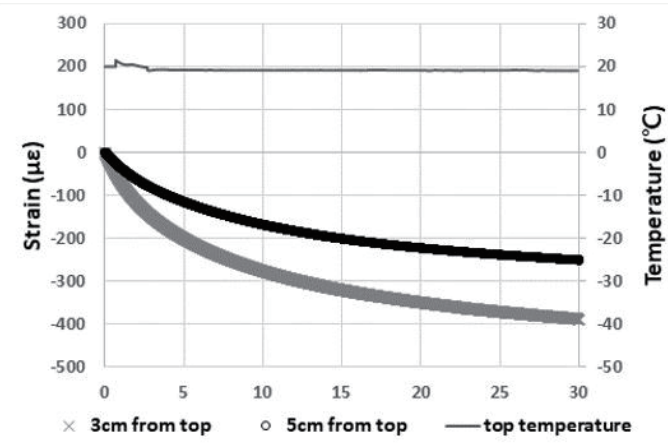

(c)

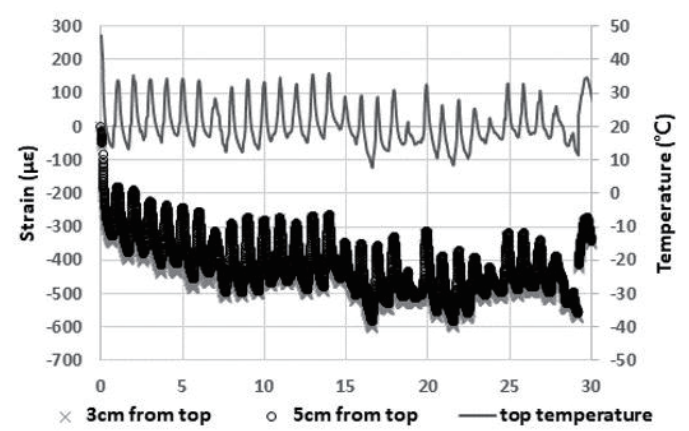

(b)

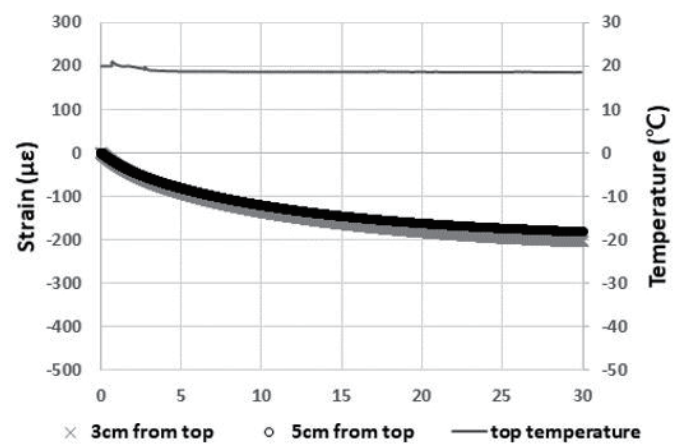

(d)

Fig. 7. Preliminary test results used to validate environment control under field and chamber conditions. (a) Field top-open specimen, (b) field all-blocked specimen, (c) chamber top-open specimen, and (d) chamber all-blocked specimen.

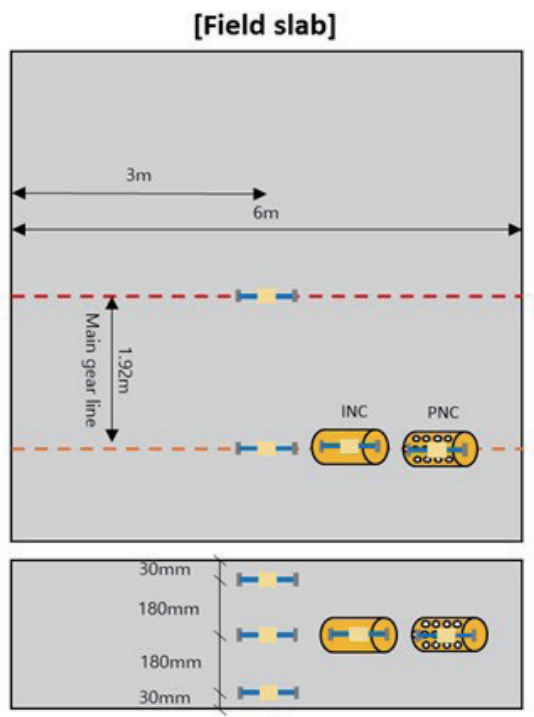

[Field beam]
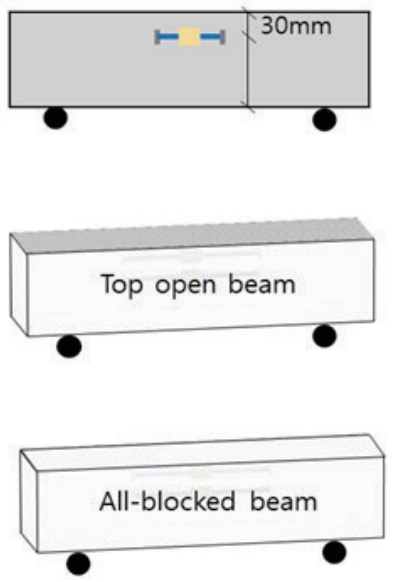

[Chamber beam]
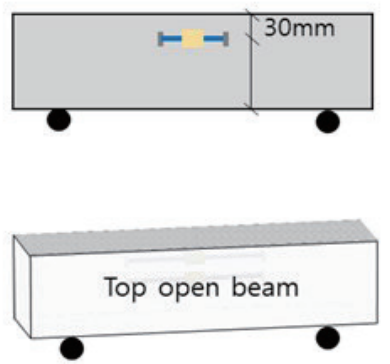

All-blocked beam

Fig. 8. (Color online) Schematic showing field-sensor application. 
Table 3

Sensors used for evaluation (NC: non-stressed cylinder, INC: impervious, PNC: porous NC).

\begin{tabular}{|c|c|c|c|c|c|c|c|c|}
\hline \multicolumn{3}{|c|}{ Field slab } & \multicolumn{3}{|c|}{ Field beam } & \multicolumn{3}{|c|}{ Chamber beam } \\
\hline \multicolumn{2}{|c|}{ Location } & EA & \multicolumn{2}{|c|}{ Location } & EA & \multicolumn{2}{|c|}{ Location } & EA \\
\hline \multirow{3}{*}{ Center } & Top & 1 & \multirow{3}{*}{ Top open } & \multirow{3}{*}{ Top } & \multirow{3}{*}{1} & \multirow{3}{*}{ Top open } & \multirow{3}{*}{ Top } & \multirow{3}{*}{1} \\
\hline & Middle & 1 & & & & & & \\
\hline & Bottom & 1 & & & & & & \\
\hline \multirow{2}{*}{$\mathrm{NC}$} & INC & 1 & \multirow{2}{*}{ All blocked } & \multirow{2}{*}{ Top } & \multirow{2}{*}{1} & \multirow{2}{*}{ All blocked } & \multirow{2}{*}{ Top } & \multirow{2}{*}{1} \\
\hline & PNC & 1 & & & & & & \\
\hline \multicolumn{2}{|c|}{ Total } & 8 & \multicolumn{2}{|c|}{ Total } & 2 & \multicolumn{2}{|c|}{ Total } & 2 \\
\hline
\end{tabular}

The total strain at different depths of the strain system directly embedded in the field slab shows that shrinkage continues to progress after the peak temperature is reached owing to the hydration of concrete. As expected, the strain at a depth of $3 \mathrm{~cm}$ from the surface of the concrete slab was the largest, and the strain at the bottom was the smallest. Figure 9 shows that in the process of concrete drying, the distributions of moisture and temperature inside the pavement are not uniform. Given that the bottom part is constrained, larger shrinkage is observed on the surface of the concrete.

By the methodology presented herein, the total strain under five different environmental conditions was derived, as shown in Fig. 10. In the case of the field specimens, the results showed that the fluctuation pattern was identical between specimens because the top-open and the all-blocked specimens were subject to the same temperature condition; the total shrinkage of the all-blocked specimen wherein drying shrinkage was prevented was smaller. Clear differences in the shrinkage of the chamber specimens were confirmed because the temperature and humidity conditions were controlled at constant values. For the total strain on the slab surface, a smaller fluctuation pattern than that of the beam specimen was confirmed. This indicates that given that only the top of the slab was exposed to the external environment, compared with the

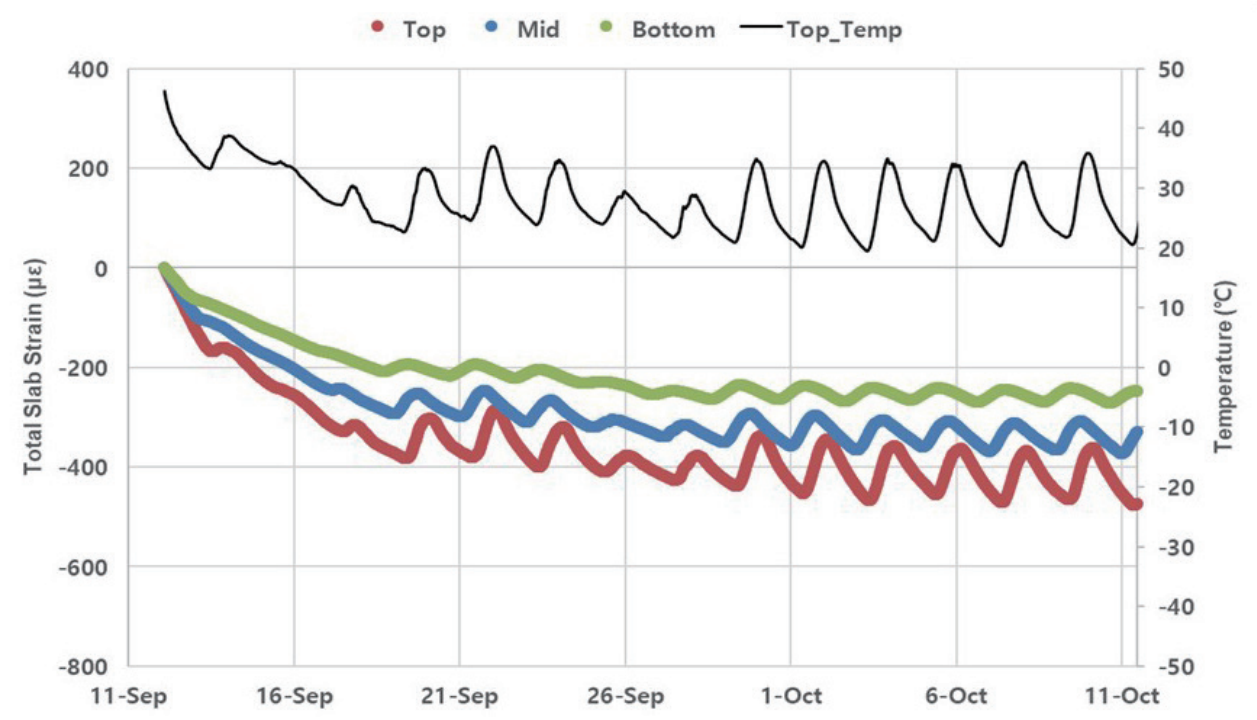

Fig. 9. (Color online) Plots of total strain of field slab at different depths as a function of time. 


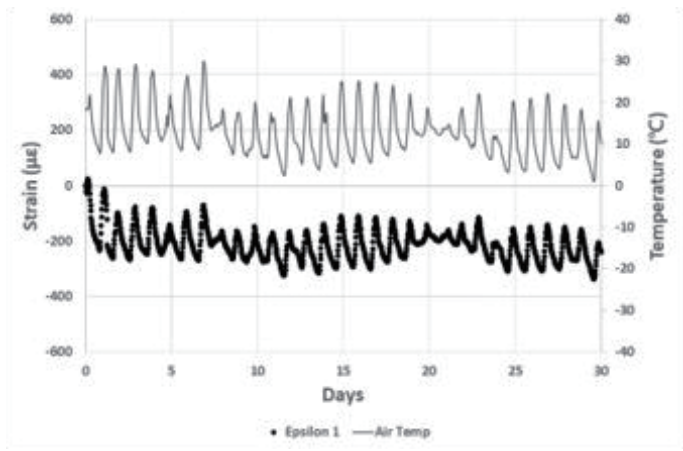

(a)

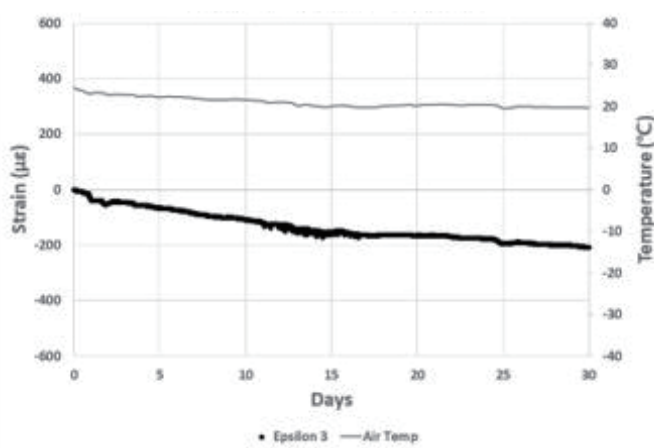

(c)

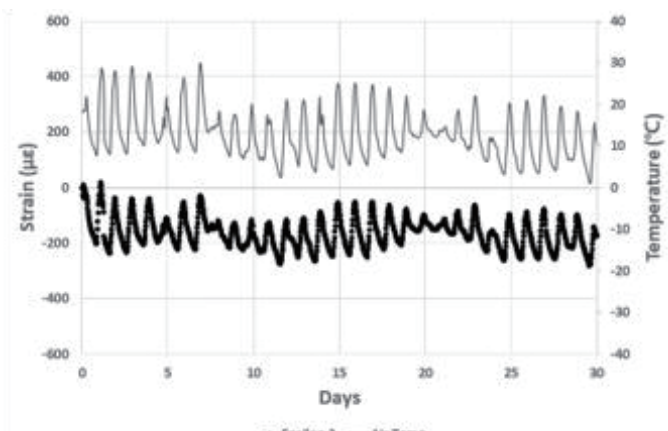

(b)

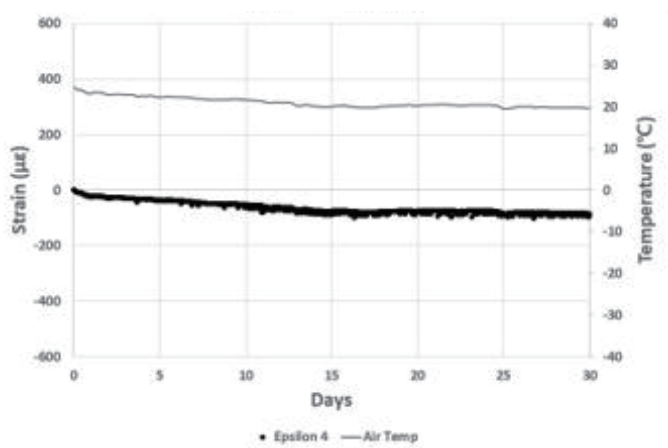

(d)

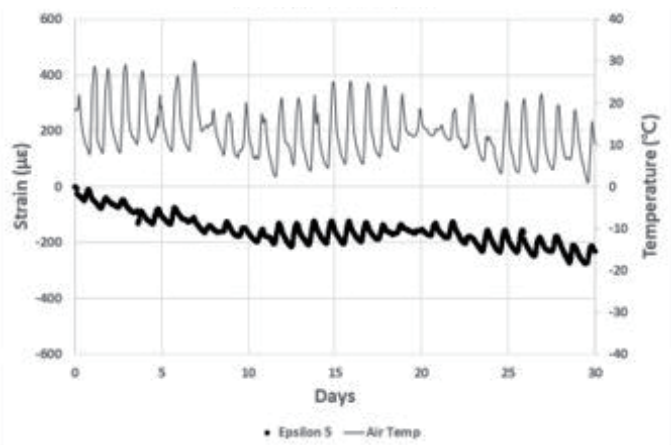

(e)

Fig. 10. Results of independent shrinkage strain. (a) $\varepsilon_{1}$ : Field top-open specimen $\left(\varepsilon_{t h}+\varepsilon_{d r y}+\varepsilon_{A u t o}\right)$, (b) $\varepsilon_{2}$ : Field allblocked specimen $\left(\varepsilon_{t h}+\varepsilon_{\text {Auto }}\right)$, (c) $\varepsilon_{3}$ : Chamber top-open specimen $\left(\varepsilon_{d r y}+\varepsilon_{\text {Auto }}\right)$, (d) $\varepsilon_{4}$ : Chamber all-blocked specimen $\left(\varepsilon_{\text {Auto }}\right)$, and (e) $\varepsilon_{5}$ : Field slab $\left(\varepsilon_{t h}+\varepsilon_{d r y}+\varepsilon_{\text {Auto }}\right)$.

entire area in the case of a beam specimen, the effect of thermal strain was reflected in the result.

\subsection{Comparison analysis of drying shrinkage derivation methods}

In the conventional $\mathrm{NC}$ method, the drying shrinkage strain was derived by subtracting the INC strain (which is subject only to changes in temperature) from the PNC strain with arbitrary changes in the temperature and humidity. However, by this conventional method, it is difficult to measure the drying shrinkage on the surface of a real slab because the strain can be measured 
only at a depth of at least $5 \mathrm{~cm}$ from the surface. As shown in Fig. 11, the evaluation results of the drying shrinkage strain obtained by the proposed and NC methods using the same material were compared.

In the case of the NC method, drying shrinkage strain values of up to $-52 \mu \varepsilon$ were calculated, whereas the drying shrinkage strain obtained by the newly proposed method where the sensor was embedded at a depth of $3 \mathrm{~cm}$ from the surface was calculated to have a maximum of $-80 \mu \varepsilon$, thus yielding $54 \%$ higher strain than that obtained by the conventional method.

\subsection{Comparison of analysis of stress-dependent strain derivation methods}

The non-stressed state is the state of no resistance to the shrinkage and expansion of the concrete mixture by the environmental load; this state can be reproduced by fabricating environment-controlled beam specimens. However, the bottom of a real slab is constrained by the self-weight, which acts as a stress resisting shrinkage/expansion.

To derive the stress-dependent strain, it is important to measure the non-stressed strain caused by the early-age hydration and environmental factors. According to basic concepts, it is reasonable to calculate the stress-dependent strain as the difference between the total strain of a slab with restraints at the bottom part and the field top-open beam specimen. However, given that the degree of exposure to the ambient temperature is different, it is important to eliminate

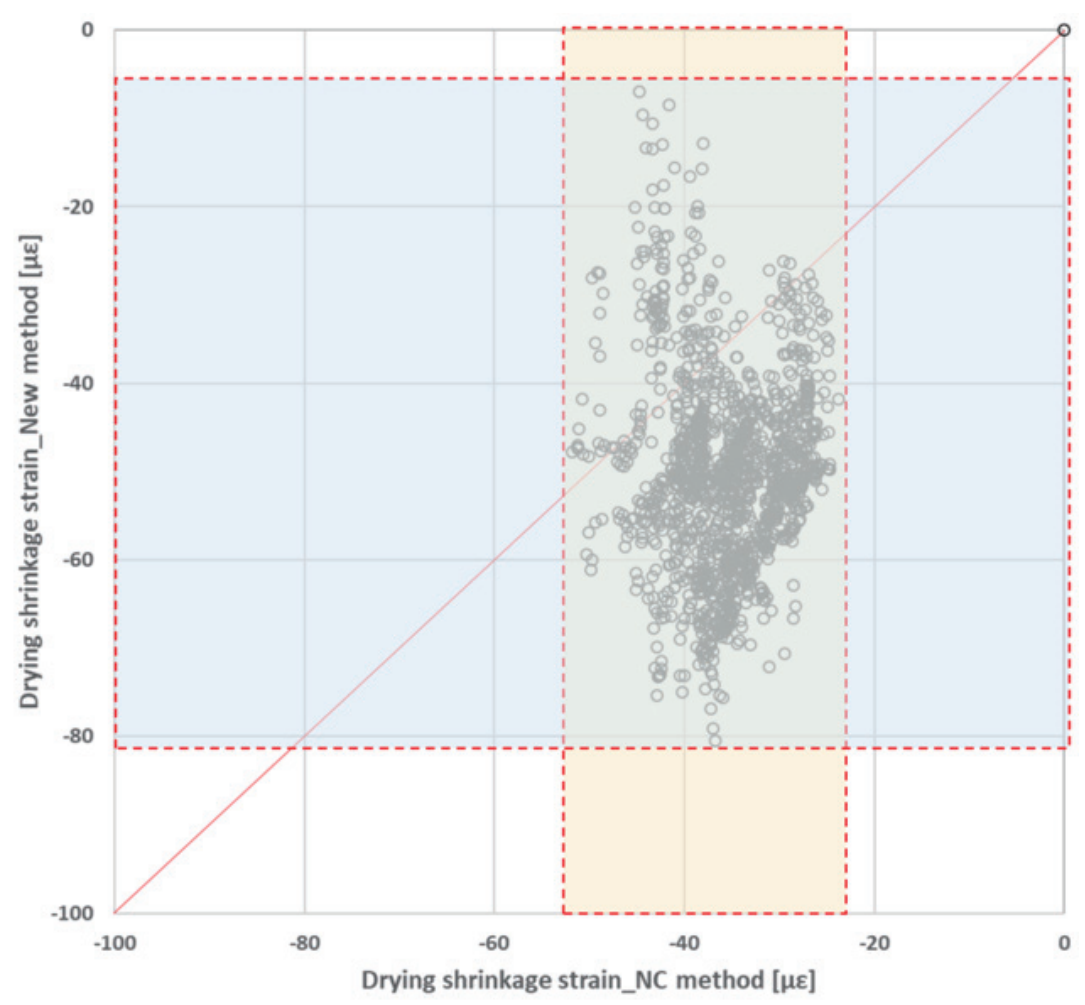

Fig. 11. (Color online) Comparison analysis of dry shrinkage strain calculated by the newly proposed and NC methods. 
only the thermal strain from the total strain in each case. In the case of the slab, the coefficient of thermal expansion (COTE) was derived from the slope of the temperature-strain graph, and the value multiplied by the temperature difference $(\Delta T)$ was subtracted from the total strain. In the case of a beam specimen, the thermal strain was calculated by subtracting the total strain of the chamber all-blocked specimen from that of the field all-blocked specimen, and this was subtracted from the total strain of the field top-open specimen to derive the stress-dependent strain.

Figure 12 shows the strain-dependent plots after the thermal strain was subtracted. The fluctuation due to the daily temperature difference was eliminated, and given that the other conditions were identical, the difference between the two values can be interpreted as the strain corresponding to the stress caused by the restraint of the slab. As a result, as shown in Fig. 13, it can be observed that a tensile strain of approximately $100 \mu \varepsilon$ occurred. Thus, with the newly proposed method, it was possible to derive the stress-dependent strain value in a more intuitive and clearer manner than the conventional NC method.

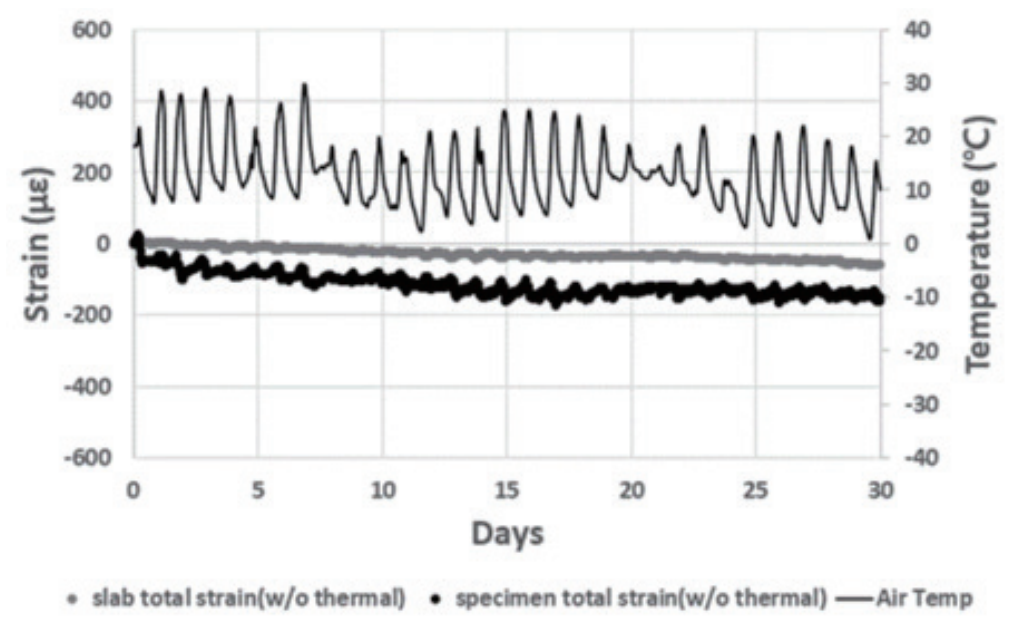

Fig. 12. Total strain of slab and specimen (thermal strain was excluded).

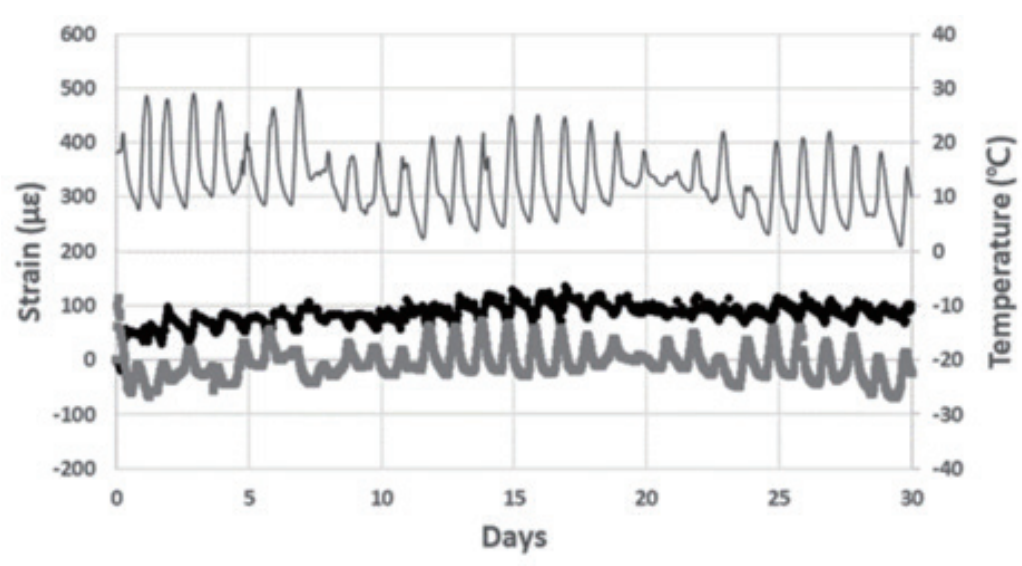

- Stress Dependent Strain (new method) = Stress Dependent Strain (NC method) — Air Temp

Fig. 13. Comparison analysis of stress-dependent strain of newly proposed and NC methods. 


\section{Conclusions}

In this study, an intuitive new methodology associated with the evaluation of shrinkage strain was developed by addressing the limitation of the conventional measurement of drying shrinkage strain, which is critically affected by the slab surface, and by controlling the factors in early-age shrinkage. The proposed method is convenient, reliable, and can be used to evaluate the shrinkage strain of field concrete pavement. Its superiority was verified by comparatively analyzing its results with that of the conventional measurement methodology of the non-stressed system in field applications.

Strain behavior was evaluated by installing a strain gauge on the surface of the slab specimen and four types of non-stressed specimens: top-open and all-blocked specimens covered with aluminum tape placed in the field and in an environment-controlled chamber. By using nonstressed beam specimens under controlled temperature and humidity conditions, autogenous shrinkage, drying shrinkage, and thermal strain were derived. After the elimination of the temperature effect from the slab, which was restrained at its bottom part, and the non-stressed beam specimen, the tensile stress and strain applied to the actual slab were calculated from the difference in strain. Thus, this method can be applied to the evaluation of early cracks.

Autogenous shrinkage was measured from the strain of the all-blocked specimen placed in an environmental chamber. This was based on the concept that there was no temperature/humidity change or moisture loss. Thus, only autogenous shrinkage strain was measured. The results showed that the lower the $\mathrm{w} / \mathrm{c}$ ratio, the larger the measured autogenous shrinkage strain.

Drying shrinkage strain is a key factor used for the control of construction and curing quality. It was calculated by subtracting the total strain of the all-blocked specimens from the strain of the field top-open specimen. Given that the conventional laboratory test or NC concept is limited in that it does not reflect the effect of drying shrinkage in the field, the new method reflects an improvement in this aspect. As a result of comparative analysis with the conventional NC concept method, approximately 54\% higher drying shrinkage strain was measured under the same conditions. Thus, the effect of drying shrinkage on the real-world pavement can be evaluated quantitatively.

Finally, in the case of stress-dependent strain, unlike the non-stressed beam specimen with free shrinkage/expansion, a stress-dependent strain response was obtained as it occurred in the slab restrained at its bottom part. By using the basic concept, the stress-dependent strain was calculated by subtracting the total strain of the top of the slab from that of the field top-open beam specimen. However, in the case of the beam specimen, unlike the slab in which only the surface was exposed to the environment, the temperature effect occurred across the entire surface; the stress-dependent strain was calculated from the total strain after the thermal strain was subtracted. As a result, a tensile strain of approximately $100 \mu \varepsilon$ was calculated, which enabled the derivation of more intuitive and clearer results than those obtained by the conventional NC method.

The superiority of the improved measurement methodology of early-age shrinkage strain in field concrete (based on the use of non-stressed beam specimens proposed in this study) was verified by comparisons with the conventional method; however, to establish the allowable 
criteria for each shrinkage and stress-dependent strain type, a sensitivity analysis is required. Furthermore, additional research is needed to propose an optimal mix design suitable for the environmental conditions in the field, such as changes in the autogenous shrinkage strain according to curing method and $\mathrm{w} / \mathrm{c}$ ratio.

This paper presents a health monitoring methodology for long-life concrete pavement. It can be used as a quality control method during the initial hydration reaction of concrete pavement. Independent shrinkage behavior can be classified to examine whether the cause of the initial quality problem occurred from the material or the construction.

\section{Acknowledgments}

We conducted this study with support from the Ministry of Land, Infrastructure and Transport, and the Korea Agency for Infrastructure Technology Advancement under the traffic and distribution project "Development of high-performance concrete pavement maintenance technology to extend roadway life" (21POQW-B146707-04). We express our gratitude to everyone involved.

\section{References}

1 M. H. Zhang, C. T. Tam, and M. P. Leow: Cem. Concr. Res. 33 (2003) 1687. http://doi.org/10.1016/S00088846(03)00149-2

2 I. Pane and W. Hansen: Mater. Struct. 35 (2002). https://doi.org/10.1007/BF02482107

3 E. Holt: Early Age Autogenous Shrinkage of Concrete, Technical Research Center of Finland ESPOO (VTT Publications, 2001) p. 446.

4 L. Wu, N. Farzadnia, C. Shi, Z. Zhang, and H. Wang: Constr. Build. Mater. 149 (2017) 62. https://doi. org/10.1016/j.conbuildmat.2017.05.064

5 Y. Lee, S. T. Yi, M. S. Kim, and J. K. Kim: Cem. Concr. Res. 36 (2006) 1268. https://doi.org/10.1016/j. cemconres.2006.02.011

6 J. Tanesi, G. L. Crawford, M. Nicolaescu, R. Meininger, and J. M. Gudimettla: Transp. Res. Rec. 2164 (2010). https://oi.org/10.3141/2164-07

7 I. Maruyama and A. Teramoto: Cem. Concr. Res. 41 (2011) 380. https://doi.org/10.1016/j.cemconres.2011.01.003

8 I. Maruyama, A. Teramoto, G. Igarashi: Mater. Struct. 47 (2013) 27. https://doi.org/10.1617/s11527-013-0042-4

9 S. Choi and M. C. Won: ACI Mater. J. 107 (2010) 498. https://doi.org/10.14359/51663970

10 M. Wyrzykowski and P. Lura: Cem. Concr. Compos. 35 (2013) 49. https://doi.org/10.1016/j. cemconcomp.2012.08.010

11 M. Nehdi and A. M. Soliman: Proc. Inst. Civ. Eng. Constr. Mater. 164 (2011). https://doi.org/10.1680/ coma. 900040

12 K. H. Yang, J. H. Cheon, and S. J. Kwon: Comput. Concr. 19 (2017). https://doi.org/10.12989/CAC.2017.19.2.211

13 C. G. Hoover and Z. P. Bažant: J. Eng. Mech. 140 (2014). https://doi.org/10.1061/(asce)em.1943-7889.0000627

14 M. Viviani, B. Glisic, and I. F. C. Smith: Cem. Concr. Compos. 29 (2007) 435. https://doi.org/10.1016/j. cemconcomp.2007.01.005

15 H. Mihashi and J. P. Leite: J. Adv. Concr. Technol. 2 (2004) 141. https://doi.org/10.3151/jact.2.141

16 J. Zhang, D. Hou, and Y. Han: Constr. Build. Mater. 29 (2012) 230. https://doi.org/10.1016/j. conbuildmat.2011.09.022

17 M. J. Ole and F. H. Per: Cem. Concr. Res. 31 (2001) 1859. https://doi.org/10.1016/S0008-8846(01)00501-4

18 Y. Guan, Y. Gao, R. Sun, M. C. Won, and Z. Ge: Front. Struct. Civ. Eng. 11 (2017) 338. https://doi.org/10.1007/ s11709-017-0411-0

19 S. Rahimi-Aghdam, M. Rasoolinejad, and Z. P. Bažant: J. Eng. Mech. 145 (2019). https://doi.org/10.1061/(asce) em.1943-7889.0001591

20 P. Lura and O. M. Jensen: Mater. Struct. 40 (2006) 431. https://doi.org/10.1617/s11527-006-9180-2 
21 J. H. Yeon, S. Choi, S. Ha, and M. C. Won: J. Transp. Eng. 139 (2013). https://doi.org/10.1061/(asce)te.1943$\underline{5436.0000451}$

22 J. H. Yeon, S. Choi, M. C. Won: Constr. Build. Mater. 38 (2013) 306. https://doi.org/10.1016/j. conbuildmat.2012.07.111

23 B. H. Nam, J. H. Yeon, and Z. Behring: Constr. Build. Mater. 73 (2014) 261. https://doi.org/10.1016/j. conbuildmat.2014.09.073.

24 M. Wyrzykowski and P. Lura: Cem. Concr. Res. 53 (2013) 25. https://doi.org/10.1016/j.cemconres.2013.05.016.

25 J. H. Yeon, S. C. Choi, and M. C. Won: Constr. Build. Mater. 40 (2013) 492. https://doi.org/10.1016/j. conbuildmat.2012.10.013

\section{About the Authors}

Jaewook Ku received his B.S. degree from Chung-Ang University, Korea, in 2005. Since 2005, he has been working at Korea Expressway Corporation (SMART Highway R\&D Division and Construction Division). His research interests are in highway design, pavement M\&R strategies, and measurement of road structures. (imweeping@ex.co.kr)

Seunghyun Roh received her B.S. degree from Korea University, Korea, in 2016 and her M.S. degree from Chung-Ang University, Korea, in 2018. Her research interests are in road and airport pavements, facilities management systems, and road structure condition indices. (shroh8@naver.com)

Hyunsik Hwang received his B.S. and M.S. degrees from Chung-Ang University, Korea, in 2016 and 2018, respectively. His research interests are in road and airport pavements, pavement management systems, and measurement of road structures. (hshwang@cau.ac.kr) 